\title{
Violence against Elderly Migrants and Its Consequences on Their Health: Experience from Monterrey, Mexico
}

\author{
Arun Kumar Acharya ${ }^{*}$ \\ 1 Universidad Autónoma de Nuevo León, Instituto de Investigaciones Sociales, Av. Lázaro Cárdenas Ote. y Paseo \\ de la Reforma S/N, Campus Mederos U.A.N.L., C.P. 64930, Monterrey, Mexico
}

Elderly migrants Informal economy Violence and abuse Health vulnerability Mexico

\begin{abstract}
In this paper, an attempt has been made to analyse how the violence and abuse against elderly migrants in Monterrey, Mexico affects their health. For this research, 257 elderly Mexican migrants were surveyed in the Metropolitan Area of Monterrey during 2012 through 2013. The study found that the majority of elderly people migrate to urban areas in search of a better economic opportunity. Once in the city, they are absorbed into the informal economic sectors. Results indicate that most of these elderly people suffer physical, sexual and psychological violence, as well as neglect and financial abuse from their employer, relatives, clients and pedestrians, which has an adverse effect on their health. Elderly migrants reported numerous health problems, where many of them were suffering from different types of injuries, stress and depression, among others. This paper concluded that violence suffered by elderly migrants has a significant impact on their health.
\end{abstract}

\section{Introduction}

Population ageing is now a predominant demographic issue and for the first time in world history our global population will no longer be young, owing to lower fertility, increased child survival and better health (UNFPA 2012). Population ageing is happening in all regions and in countries at various levels of development. In the case of Mexico, the elderly population has

\footnotetext{
*Contact address: acharya_77@yahoo.com (A.K. Acharya)
} 
increased from 5\% in 1960 to $9 \%$ in 2009 and expected to reach $28 \%$ by 2050 (United Nations 2013). This change in the demographic pyramid will profoundly impact economic, political, social conditions as well as in health services (Centro de Estudios Sociales y de Opinión Pública 2011). In 2010, the median age of Mexican population is 26 years, meaning there were equal numbers of people above and below age 26, which was 22 years in 2000 and 19 years in 1990s. This reflects that the number of older adults is growing faster than the number of young adults and children (Rhoda and Burton 2010).

Moreover, the study of Rhoda and Burton (2010) indicates that, in 2010, about $29.3 \%$ of the Mexican population was under the age of 15 , compared to $34.1 \%$ in 2000 and $38.6 \%$ in 1990 . On the other hand, the 2010 census reflects that $6.3 \%$ are over age 65 , up from $5.0 \%$ in 2000 and only $4.2 \%$ in 1990. This information reflects that in the last two decades, the elderly population in Mexico has increased by $50 \%$ and these changes are quite dramatic and represent a major demographic challenge for health services, elderly care systems and regional demographic imbalance through migration. The Mexican population census data on inter-states migration shows that: in 2000 there were about 132,643 migrants aged 60+ in the country, which rose to 151,446 in 2010 , where $50 \%$ of these migrants come from only eight states ${ }^{1}$ and most of them are permanent.

The National Survey on Dynamic of Household Relations (2011) indicates that $18.6 \%$ of elderly Mexicans have suffered some kind of violence during the last twelve months. There is evidence that recently in Mexico the violence against elderly has increased (Quadratín 2014; Docampo Santaló, Barreto Lacaba, and Santana Serrano 2009), while the number of elderly migrants in Mexico has grown (Notimex/Union Guanajuato 2013; JuárezRamírez et al. 2014). Thus, the question arises: why elderly people are migrating in Mexico? Do these migrants suffer from discrimination and violence at the destination? And, if so, what kind of violence and discrimination do they face in their day-to-day life and how these affect the

\footnotetext{
${ }^{1}$ Morelos, Michoacán, Querétaro, Aguascalientes, Guanajuato, Oaxaca, Tlaxcala, and Puebla.
} 
health of the elderly migrants? Considering the above questions, the main aim of this paper is to analyse the type of discrimination and violence suffered by elderly migrants at their work place, as well as at home (if any) and its impact on their health.

\section{Theoretical background}

Violence against older people by the family and non-family members is still a hidden agenda for many countries and it has remained as a private matter. In 1975 for the first time British scientific journals published violence against elderly people under the term 'granny battering' (Baker 1975; Burston 1975), which indicates the ill treatment faced by elderly persons. It has been noted that during the last few decades the increase in elderly population has brought the attention and concerns on living arrangements of the elderly (De Donder et al. 2011). In this context, the World Health Organization (WHO) defines elder violence as 'any type of action, series of actions or lack of actions, which produce physical or psychological harm and which is set within a relationship of trust or dependence'. Elder violence may be part of a cycle of family violence; it may be caused by caregivers or employers or by any other. The violence can take various forms, such as physical, psychological, sexual, financial, and neglect (WHO 2002, 7).

Physical violence: This category refers to actions carried out with the intention of causing physical pain or injury to a (vulnerable) older person. Examples: being pushed, grabbed, slapped, hit, hit by a thrown object, administering too much tranquilizing or neuroleptic medication (WHO 2002, 7).

Psychological/emotional/verbal violence: This form of violence describes all actions inflicting mental pain, anguish or distress on a person through verbal or nonverbal acts. Examples include the use of abusive language, oppression, manipulation, bullying, blackmail, shouting, threats, humiliation, isolation of the older person, or infantilizing the person (WHO $2002,8)$. 
Sexual violence: This form of violence refers to non-consensual sexual contact of any kind (e.g. unwanted intimacy, touching in a sexual way, rape, undressing in front of the victim, sexually slanted approaches).

Financial/material violence: This form of violence describes all actions of illegal or improper use of an elder's funds, property or assets (WHO 2002, 8). For example, problems with powers of attorney, swindling, disappearance of money or goods, obstruction in managing one's own money, legacy hunting, and extortion.

Neglect: This type of abuse or violence deals with the refusal or failure by those responsible to provide essential daily living assistance and/or support, such as food, shelter, health care or protection for an older person. This bears resemblance to the term abandonment, that is, neglect in its most extreme form: the desertion of a vulnerable elder by anyone who has assumed the responsibility for care or custody of that person (WHO 2002: 8).

The increase in the population of older people has resulted in bringing concerns of elder abuse (De Donder et al. 2011). During last two decades violence and abuse against elderly are documented through studies in different countries, for example, a study conducted among 975 elderly people in rural China shows that nearly $5 \%$ of elderly reported that they have faced physical violence during the last year, while around $7 \%$ reported financial exploitation and emotional violence during the same period. On a similar kind of research in the Netherlands indicates the prevalence rate of violence against the elderly is $6 \%$. The violence and aggression faced by elderly people is verbal, physical and financial aggression. Similarly, Spencer (1994), violence against the elderly causes many serious health consequences including dehydration, poor hygiene, malnourishment, fractures, pain, swelling, bleeding, high blood pressure, breathing problems, stomach problems (ulcers), panic attacks and heart problems, and in the case of sexual abuse, it may cause sexually transmitted diseases.

Similarly, a random telephone survey conducted on 804 registered nurses who provide assistance to older people in Ontario, Canada, indicates that nearly one-half of the respondents had witnessed one or more incidents 
of violence and abuse, with verbal abuse (37\%) being the most common type and followed by physical abuse (32\%) (College of Nurses of Ontario 1993).

In the case of Mexico, the information provided by the Government of Mexico City shows 1.5 million elderly people who have suffered violence and have been mistreated in their home (El Sol de México 2014). At the nation-wide level, data indicates that 17 out of 100 elderly people suffer violence, where $35.6 \%$ suffer violence from their children, $25 \%$ from their partner, $11.3 \%$ from grandchildren, and the rest from other relatives. Currently in Mexico, violence against the elderly has become an important issue for public health (INEGI 2012). A study conducted by Vargas-Daza et al. (2011) in Queretaro among 395 elderly showed that 42.3\% suffer psychological violence, $2.3 \%$ suffer sexual violence and $16 \%$ were humiliated or insulted by their family members, whereas $59 \%$ suffer from chronic diseases due to violence.

The health problems of elderly people are not only a biological or medical concern, but also a significant personal and socio-economic condition, in addition to a hazardous environment of their habitat. Although there is scarce literature available on the issue of elderly violence and its impact on health, the studies of Vargas-Daza et al. (2011), Pérez-Rojo et al. (2008), Jackson and Mallory (2009), and Sharma (2012) indicate that violence has myriad health effects beyond those sustained directly from the episode. Victims of violence have higher rates of depression, anxiety and posttraumatic stress disorder, plus worse overall health.

Based on empirical evidence, a number of theoretical models have been developed to understand violence and mistreatment against the elderly. For example, the social learning theory given by Bandura in 1978 explained that violence is a learned behaviour passed on through generations. According to this theory, people learn by observing others' behaviours, attitudes and the outcomes of those behaviours. Most of human behaviour is learn observationally through modelling. From observing others, one forms an idea of how new behaviours are performed and on later occasions this coded information serves as a guide for action. Thus, present 
theory highlights human behaviours in terms of continuous reciprocal interaction between cognitive, behavioural and environmental influences. On the other hand, social exchange theory developed by sociologist George Caspar Homans (1958) explains the interactions between people as a process of negotiated exchanges. The theory has roots in economics and psychology. Social behaviour is considered an exchange of material and non material goods. Material goods include things like money, living arrangements, inheritance, and non material goods include approval and prestige. People that receive a lot from others are under pressure to give much to them in return (Homans 1958). In 'Aging as Social Exchange: A Preface to Theory' published in 1975, Dowd wrote: power is synonymous with the dependence of one person upon another. The person who is perceived as contributing most to the relationship has the power advantage. The person with the power advantage is able to manipulate the behaviour of the dependent person. The person with the power advantage may perceive that there is little lost by being unjust (Phillips 1986). The Power and Control Theory highlights an abusive individual's use of a pattern of coercive tactics to gain and maintain power and control during the course of a relationship with another person. Brandl (2002) has adopted this theory to explain spousal abuse among elderly couples, although it could be applied as well when such traits describe an adult child or caregiver who has assumed, perhaps grudgingly, responsibility for the elderly person.

Although the above listed theories are useful, they have not been able to explain the origin, structure and prevention of violence toward the elderly adequately. Thus, in this context, the ecological theory offers a systematic description to understand the complexity of elder violence. Schiamberg and Gans (2000) examine that violence as the outcome of the interaction between individual, relational, community level and societal factors. According to these authors, the risk factors at the individual level comprise biological and personal history aspects that increase the likelihood of becoming a victim or perpetrator of violence. Some of these factors are age, education, income, substance use, or history of abuse. The second level examines close 
relationships that may increase the risk of experiencing violence as a victim or perpetrator. A person's closest social circle - peers, partners and family members - influences their behaviour and contributes to their range of experience.

The third level concerning the community that explores the settings in which an individual develops their social relationships and seeks to identify the characteristics of these settings, such as schools, workplaces, and neighbourhoods, which are associated with becoming victims or perpetrators of violence. Finally, the fourth level, societal, looks at the broad factors that help create a climate of violence toward the elderly. These factors include social and cultural norms. Other large societal factors include the health, economic, educational and social policies that help maintain economic or social inequalities among society groups.

Figure 1. Effect of migration on health

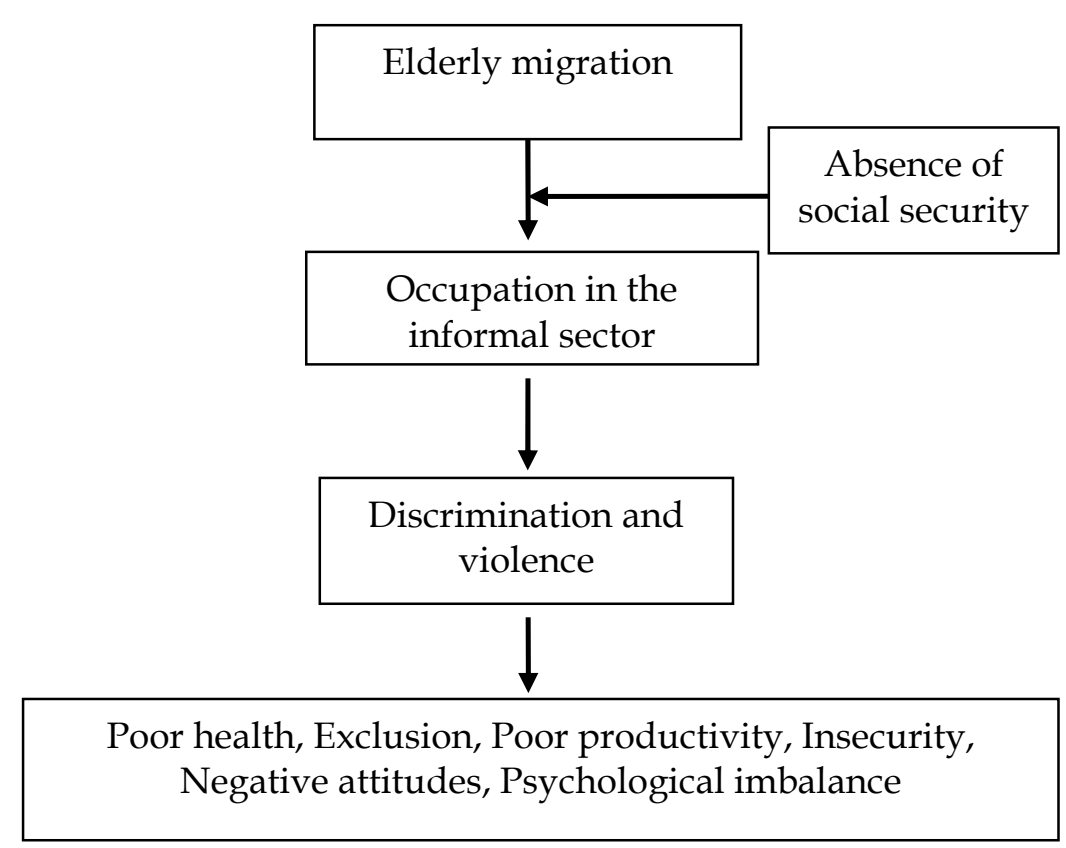

Source: Self elaboration 
Theories of violence toward the elderly have tended to explain various factors from individual to societal. In a comprehensive manner, it is necessary to understand that violence toward the elderly is a result of multilevel factors, which has a direct impact on their physical, emotional and mental health. It is true that in developed nations, elderly people have economic and social security, which contributes to the elderly suffering less violence. Whereas in developing countries, where the ageing process is a growing concern and due to a lack of social and economic security, elderly people prefer to stay with their children and grandchildren, where there is a greater probability of suffering violence, as many of their family members feel the elderly are an economic burden. To escape from such type of violence, many of these elderly people prefer to migrate to different urban centres in search of employment, mainly in the informal sector. Once they are in the city, they suffer different types of violence, discrimination as well as exclusion, which adversely affects their health (see Figure 1).

\section{Demographic profile of Mexico}

Mexico's demographic transition has followed a typical profile, the pretransitional phase that lasted until about 1930. The first stage saw a rapid decline in mortality while birth rates remained fairly steady and even rose between 1945 and 1960. The second phase began around 1970 when the decline in fertility, which began during the 1960s, became more rapid. The third stage of the process, when the birth and mortality figures converge, will occur during the first half of the twenty-first century. During the year 1921, the population growth rate was $1.4 \%$ and it was $1.7 \%$ in 1930 and further to $2.7 \%$ in 1950 and $3.5 \%$ in 1965 . As a consequence of the decline in fertility, the pace of population growth began gradually to decrease, to $3.1 \%$ in 1970, 2.3\% in 1985, 1.3\% in 2000 and currently it is less than 1\% (PartidaBush 2005).

The general drop in mortality was so rapid that the cumulative reduction in the risk of death between 1930 and 2001 amounted to $82 \%$ for 
men and $86 \%$ for women. As in many other countries, Mexican mortality decreased slowly during the 1960s. The pace of decline picked up later, but was not as rapid as in earlier years. A rapid and sustained decline in mortality took place at the beginning of the 1930s, in a context of farreaching economic, political and social reforms. Among the main determining factors of the sharp decline in mortality are the expansion of education services and sanitation infrastructure and the extension of health services. The latter has been a significant factor ever since the creation of the Mexican Social Security Institute (IMSS) in 1942 and the conversion of the Department of Health into the Ministry of Health in 1943. On the other hand, in 1930, the life expectancy at birth was 35.9 years, whereas, in 2010 it was 75.6 years. Progress was greatest between 1942 and 1960 when there was an increase of almost one year in the average length of life for each calendar year (Partida-Bush 2005).

Figure 2. Distribution of elderly people $\left(60^{+}\right)$in Mexico during 1950-2010

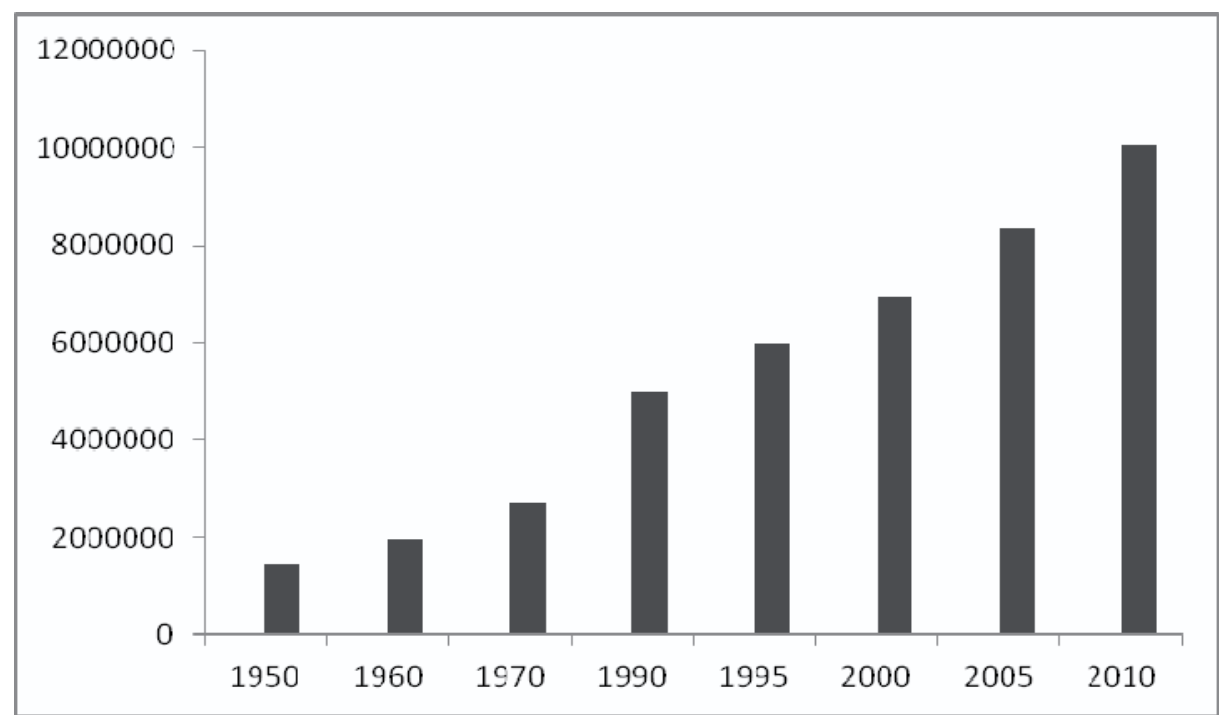

Source: INEGI 2012 
Similarly, the decline in fertility did not begin until the mid-1960s, for instance, in 1975 the total fertility rate (TFR) was six children per woman, which fell to five in 1979, four in 1985 and three in 1994, and has now decreased to 2.1 children (Partida-Bush 2005). Thus, the various phases of demographic transition have left their mark on the age structure of the Mexican population. After the 1990s we can observe a significant increase in the Mexican elderly population (see Figure 2) and, according to the Instituto Nacional de las Personas Adultas Mayores (INAPAM) about 10 million (9\% of the total population) are above 60 years of age, and it is expected to reach 15 million by 2015, and 36 million by 2050 (INAPAM 2012).

On the other hand, figure 3 shows the population changes of $0-4$ years and 60 years and more during the years 1950 to 2010. It has been observed that, after 1995 there is a steady growth in elderly population (60+ years) and at the same time, the $0-4$ population is declining. During the year 2003, there was a transition between child and elderly population in Mexico, which explained that Mexico is moving toward an ageing society (see Fig. 3 ).

Figure 3. Demographic transition in Mexico

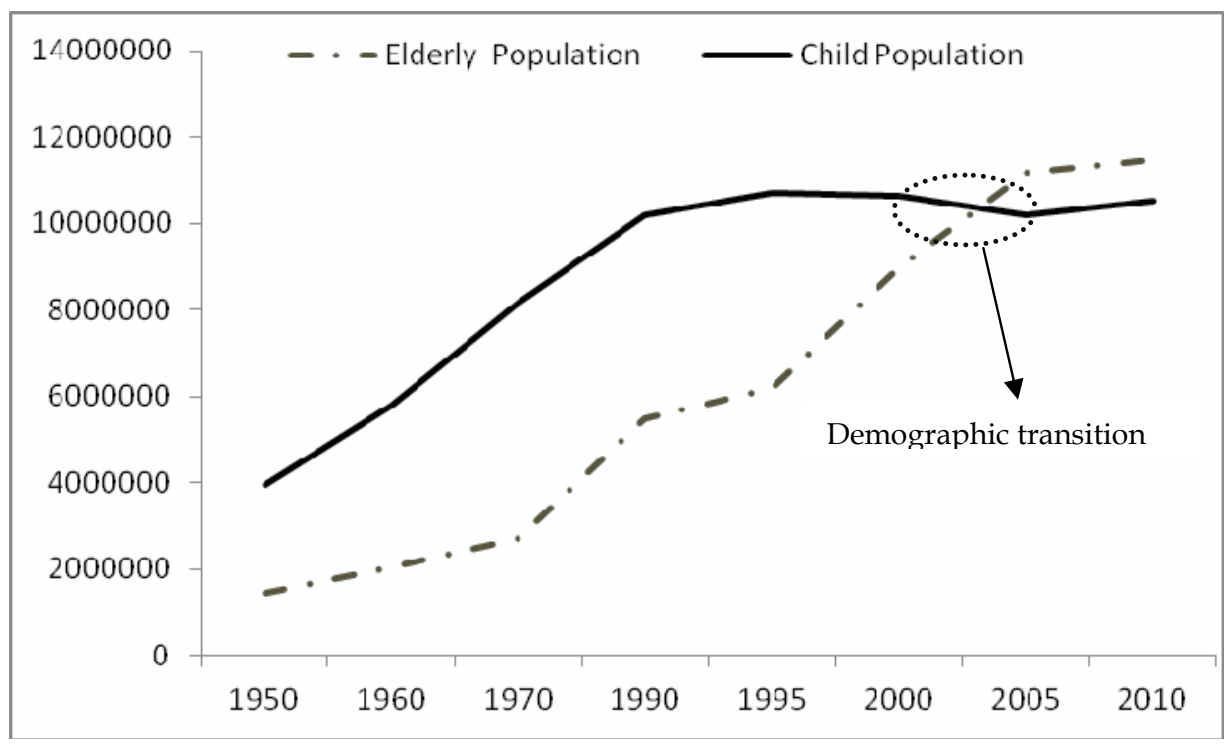

Source: INEGI 2012 
There is a clear indication that the elderly population is increasing in Mexico, but according to the Consejo Nacional de Evaluación de la Política de Desarrollo Social (CONEVAL) (2011) in 2010 around 3.5 million elderly people were suffering from multidimensional poverty, whereas around 0.8 million were suffering from extreme multidimensional poverty. Data indicates that among the 3.5 million elderly, 66.2\% were illiterate, whereas $26.3 \%$ did not have any type of health services, $28.8 \%$ did not have any type of social security and about $22 \%$ of the elderly had limited nourishment (INEGI 2012). Data of elderly people living in rural areas indicates that they need to work in order to secure a minimum income for their survival. Due to the absence of universal pension systems, any type of government aid is non-existent in rural Mexico. Thus, these elderly people prefer to migrate to urban centres in search of employment. Upon their arrival, the elderly are included in the informal sector. Figure 4 shows how the number of elderly migrants is increasing in the informal sector in Monterrey, though there is a small decrease from 2000 to 2005, but it increases again after 2008, due to the global economic crisis.

Figure 4. Number of elderly migrants in the informal sector in Monterrey

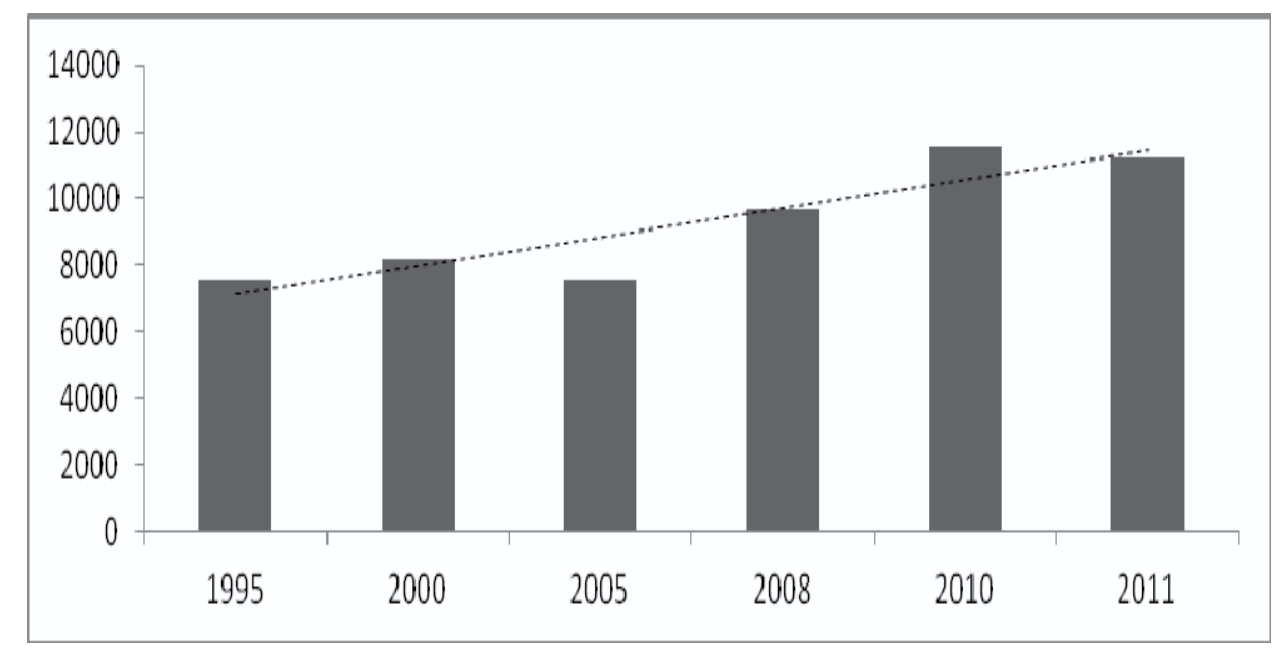

Source: INEGI, 2012 


\section{Methodology}

The present research was conducted in Monterrey, one of the highly industrialized urban centres in Mexico as well as border state with the USA The study included a quantitative approach (a structured survey), which provides a more comprehensive examination of the effect of migration on the wellbeing of elderly people in Monterrey, Mexico. The data collection was implemented during the months of December 2012 and January 2013. This quantitative method was used in the research to reveal the scale and patterns of the migration, as well as the reasons and the effect of migration on the life of elderly people in selected households; the financial situation, their main sources of income and assets, self-reported health status, violence and discrimination endured in the city were also examined. Structured interviews were conducted on 257 elderly migrants working in the informal sector, who had migrated to Monterrey two years earlier. Due to the explorative nature of this study, convenience (availability) sampling was used to recruit respondents, therefore the research results cannot be generalized, but reflect the experience of the selected elderly. Though the findings are not representative, they improve our understanding of regular patterns. The questionnaire consisted of 60 closed-ended and 19 open-ended questions. The questionnaire was designed in Spanish.

\section{Results}

\section{Socioeconomic features of elderly migrants in Monterrey}

The elderly migration is the newly emerging migratory phenomenon in the developed as well as developing countries (Rogers 1988; Siddiqui 2012). The growing migratory intensity among elderly people was further proof of the selectivity of migration by age, in addition to the very high migration probability in young adult age groups and low mobility in middle-aged groups. As described in the methodology, we interviewed 257 elderly migrants in Monterrey. Their demographic characteristics indicate that the 
majority ( $81 \%$ ) of the elderly migrants' population belongs to the age group of 61 to 70 and 80 years old, while a small part are 51 to 60 and above 80 years old. In terms of literacy and educational attainment, nearly $70 \%$ of elderly migrants have a primary and secondary level of education. Illiteracy rate is very low; around $17 \%$ never attended school. Data indicates that more than $60 \%$ of elderly migrants are currently living with their spouse, whereas one fifth of interviewees reported being widows (see Table 1).

Table 1. Demographic characteristics of elderly people in Monterrey

\begin{tabular}{|l|c|}
\hline Elderly Migrants & Percentage \\
\hline Age & 15.2 \\
$52-60$ & 44.0 \\
$61-70$ & 26.5 \\
$71-80$ & 14.3 \\
More than 80 & \\
& \\
Education & 17.1 \\
Illiterate & 39.3 \\
Up to primary & 24.5 \\
Up to secondary & 19.1 \\
Bachelor and more & \\
& \\
Marital status & 2.4 \\
Never married & 62.7 \\
Married/Living with partner & 18.5 \\
Widow & 16.4 \\
Divorced or separated & \\
\hline
\end{tabular}

Source: Data obtained from fieldwork

In terms of occupation and dynamics of employment, a significant number of elderly migrants engaged in precarious work, as Capron and Arellano (2010) stated in their study that, for elderly migrants, age is an important factor to be admitted into any type of employment sector. These categories of migrants struggle to get a decent job, thus they prefer to enter into the informal sectors. Our analysis on employment status of elderly migrants indicates that nearly $32 \%$ of migrants are engage as street vendors (see Figure 5). They sell food such as tacos, ice cream, chocolates, fruits, corn and potato chips. We have also seen that $19 \%$ of elderly migrants work as 
domestic help and gardeners. Some elderly migrants also worked as taxi drivers, at construction sites, mechanics and other activities. It is clear that there is a high segregation of elderly migration at 'outdoor jobs' (67\%), which constitutes an important concern on their health and security.

Figure 5. Occupation of elderly migrants in Monterrey in the informal sector

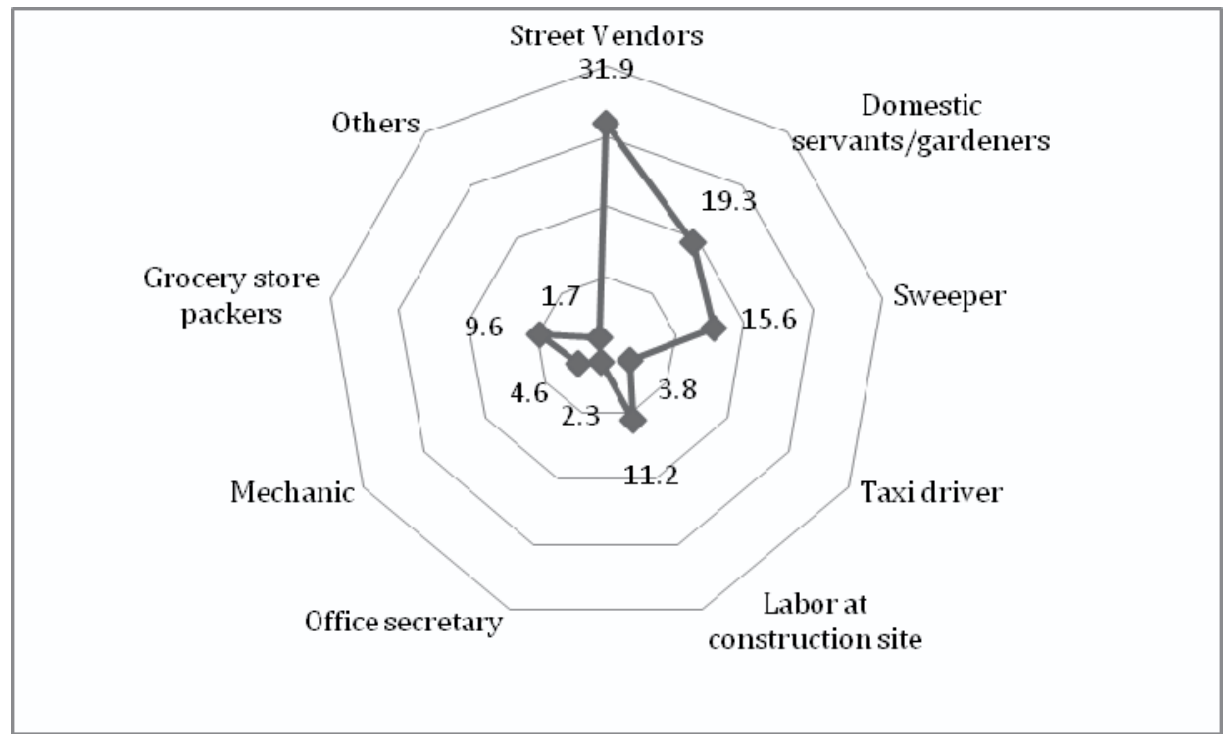

Source: Data obtained from fieldwork

To understand their quality of life, one question addressed their monthly income and the analysis found that; $12 \%$ of elderly migrants earn less than 1,500 pesos $^{2}$ per month, nearly $37 \%$ of elderly migrants indicated their monthly income is between 1,500 to 3,000 pesos per month and about $34 \%$ of migrants indicated they earn 3,000 to 4,000 pesos every month. Our result indicates that only $6.4 \%$ of elderly migrants earn between 4,000 and 5,000 pesos, however, it is surprising to see that nearly $11 \%$ earn more 5,000 pesos per month.

The analysis on dynamics of employment includes the status of

2 In Mexico 13 pesos is $\$ 1$ USD. 
employment contract, job stability and work shift. It is observed that only $14.7 \%$ of elderly migrants have an employment contract, meaning that $85.3 \%$ work without any contract, which shows a lack of job stability. Therefore, on the question related to job stability, it found that nearly $63 \%$ of migrants have a daily contact, whereas $27 \%$ of migrants said their contract is on a monthly basis, and nearly $10 \%$ of migrants have a contract for a few weeks. With respect to the question on working shifts, we have seen that the majority $(63 \%)$ of migrants work morning shifts, $20 \%$ work in the afternoon and $17 \%$ work the night-time shift. These results indicate that elderly migrants are more vulnerable to job exploitation, as they do not have a permanent and signed employment contract, and their job stability is much lower and there are migrants who are working at night-time.

\section{Violence and abuse against elderly people and its impact on health}

Sethi et al. (2011) described that neglect, abuse and violence against older adults, are referred to as mistreatment of older adults, or elder abuse. In this context, Schiamberg and Gans (2000) identified in their ecological theory that violence or abuse is an outcome of the interaction between individual, relational, community level and societal factors. Violence and abuse of elderly people is an important public health problem all over the world, as there is little information available regarding the extent of the problem, it makes it difficult for government and non-government organizations to make decisions in favour of this issue. In this section, I have identified the forms and extension of violence and abuse faced by elderly people in Monterrey, at work as well as outside the work place.

The following figure illustrates violence and abuse suffered by elderly migrants. During the interviews, we asked what types of violence and abuse they have suffered during the last twelve months. Our results indicate that 93.6\% of migrants suffered psychological violence, such as insults, being scolded, threatened and ignored by their employers, clients and family members, whereas $86.3 \%$ responded they have suffered physical violence 
such as being beaten and having objects thrown at them by their employers, clients or pedestrians. About $89.3 \%$ have faced financial abuse, such as not being paid for their work, having money stolen, working overtime or being paid less by their employer; $92.1 \%$ indicated their family members neglected them, for example did not visit them, did not provide food for them or did not take them for medical check-ups. Similarly, 56.7\% reported they had faced sexual violence ${ }^{3}$, where employers, clients, partners and pedestrians were the abusers.

Figure 6. Type of violence and abuse suffered by elderly migrants during 12 months

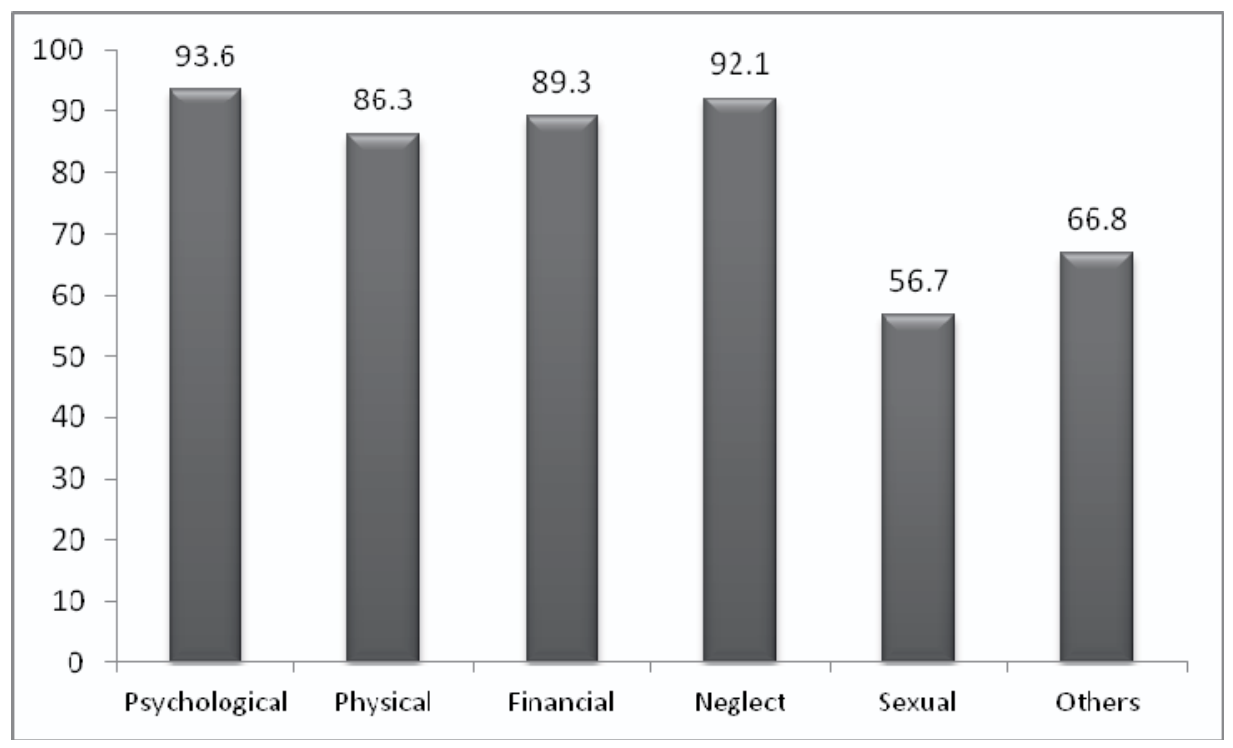

Source: Data obtained from fieldwork

As seen on the above analysis, elderly migrants suffer various types of violence and abuse. A number of situations are responsible and put elderly migrants in a violent situation, adversely affecting their health. In the first part of this section, I have examined the current health status of elderly

\footnotetext{
${ }^{3}$ In our analysis sexual abuse covers all types of non-consensual sexual contact and nonconsensual sexual acts. Sexual contact with any person incapable of giving consent is also considered sexual abuse.
} 
people, and later correlate how this violence causes various injuries and health problems among elderly migrants. Analysis indicates that $26 \%$ of elderly migrants reported they have good or fair health, whereas nearly $74 \%$ of migrants have a perception of poor health.

When we asked about their general health problems, we found that more than half of the elderly migrants (both male and female) reported having various physical problems. Problems such as joint and muscle pain, stress, feeling weak and skin illnesses were common for both men and women. However, hearing, vision and memory loss problems were some other ailments represented and reported by elderly migrants (see Table 2).

Table 2. General health problems reported by elderly migrants

* Multiple responses

\begin{tabular}{|l|c|}
\hline Health problem & Percentage \\
\hline Joint pain & 93.5 \\
Hearing problem & 37.3 \\
Vision problem & 41.6 \\
Feeling weak & 80.5 \\
Memory loss & 22.7 \\
Skin disease & 83.6 \\
Muscles pain & 91.4 \\
Stress & 93.6 \\
\hline
\end{tabular}

Source: Data obtained from fieldwork

From the above analysis, it is assumed that most of elderly migrants suffer many kinds of diseases, including high and low risk. Yet when migrants were asked to respond to any type of injury or health problems they had as a result of violence or abuse suffered during the last 12 months, most migrants relate their health to violence and abuse they suffered. The result of this analysis we have presented in Table 3.

In this study, I have classified and analysed the prevalence of high-risk diseases suffered by elderly migrants in Monterrey. The percentage of highrisk diseases such as obesity, diabetes and high \& low blood pressure are significantly higher among both men and women. More than half of interviewed elderly migrants reported having these problems. However, the prevalence of diseases such as heart disease is higher among males (43\%) 
than females $(22 \%)$. Other high-risk diseases such as asthma and urinary problems are also high among elderly migrants.

Table 3. Prevalence of injury and health problems due to violence and abuse suffered

\begin{tabular}{|l|c|}
\hline Health problem & Percentage \\
\hline Head injury & 43.5 \\
Stress & 93.6 \\
Musculoskeletal & 41.4 \\
Depression & 92.5 \\
Eating disorders & 82.7 \\
Anxiety & 87.6 \\
Excess alcohol use & 34.4 \\
Joint problems & 93.5 \\
Abdominal problem & 89.0 \\
Cuts and burn marks & 52.3 \\
Genital infections & 9.6 \\
\hline
\end{tabular}

Source: Data obtained from fieldwork

To assess the impact of violence on health, I took into consideration the different variables of violence and abuse suffered by elderly migrants during last 12 months. Table 4 shows the relationship between violence and abuse on the health of elderly migrants. Elderly migrants who faced physical and sexual violence reported poor health conditions as compared to other violent acts such as neglect, or psychological and financial abuse.

Table 4. Impact of violence and abuse on heal th of elderly migrants

\begin{tabular}{|l|c|c|}
\hline Type of violence and abuse & Fair health & Poor health \\
\hline Physical & 9.3 & 90.7 \\
Sexual & 1.2 & 98.8 \\
Neglect & 37.9 & 62.1 \\
Financial & 27.1 & 72.9 \\
Psychological & 16.4 & 83.6 \\
\hline
\end{tabular}

Source: Data obtained from fieldwork

On the contrary, I have done a similar bi-variate analysis taking into 
consideration all types of violence and with two major acute elderly health problems, i.e. depression and stress. Results indicate that elderly people who have suffered physical, sexual and psychological violence reported greater health problems which was also confirmed by the chi-square test establishing statistically significant $\left(\chi^{2}=83.05\right.$ is significant at 0.05 level) in the self-assessment of the health condition between the group of elderly who had experienced violence. Thus, this study demonstrated that there is a strong association between the violence and abuse suffered by elderly migrants and their health.

\section{Conclusion}

Violence against elderly people includes psychological, physical, and sexual abuse, neglect and financial exploitation. Evidence suggests that 1 out of 10 people above 60 years of age experiences some form of elder abuse, and only a fraction of cases are actually reported to social services agencies. At the same time, elder abuse is independently associated with significant morbidity and premature mortality. Due to a lack of significant social security facilities for elderly people in Mexico, many of these age group populations prefer to migrate to cities in search of employment.

Migration is a fact of today's globalised world and progressively a necessary component of economic and social development everywhere. As migration is increasingly becoming a part of life, the health implications of migration and the health of migrants need to be recognized as an important issue in health policies. Migrants go through several experiences, which ultimately affect their health particularly in settings where they face a combination of social, cultural, economic and behavioural barriers during the migration process. Socioeconomic inequalities exist in every society and among different societies, meaning that the freedom to lead flourishing lives and enjoy good health are unequally distributed amongst different population groups, and migrants frequently find themselves amongst those 
most negatively affected by these imbalances, as we observed from our earlier discussion.

It is evident from the study that there is an increasing number of elderly people in the migration network, who migrate in search of employment and better opportunities, as they do not receive any social security from government, and for some elderly people, their pension is not even sufficient. Insufficient employment opportunities in the formal sector for elderly people push them into the informal sector, where they work as street vendors, taxi drivers, mechanics, sweepers and domestic help without an employment contract or social security. As we have seen from the analysis, elderly migrants do not earn according to their expectation. The majority of elderly migrants earn between 1,500 and 3,000 pesos per month. There is therefore a strong discrimination against elderly migrants in term of salary as well as in their working hours and days. The study found that these migrants have hardly enough time to rest during the weekend. For most of them, the weekends do not exist. Some migrants work six days a week and many of them work seven days a week.

Our analysis on the health status of elderly migrants, as expected, showed that many migrants report various health problems, but the most common health issues faced by migrants are joint and muscle pain, stress and feeling weakness. Similarly, the analysis indicates there is a high prevalence of risk diseases such as depression and stress among elderly migrants, which significantly point out the poor and alarming health outcomes among the groups. However, our bi-variate analysis on the type of violence and health outcomes indicates there is a correlation between these variables. Elderly migrants who have suffered physical, sexual and psychological violence have reported higher percentages of health problems. Overall, we have obtained a considerable association between violence and poor health status among the elderly migrant population. As indicated on the literature on migration, ageing and health, violence and abuse have greater impact on the health status of the older population. It is therefore 
very important, from a public policies standpoint, that Mexico take urgent measures to reduce the violence and abuse against the elderly population.

\section{References}

Brandl, Bonnie. 2002. "Power and Control: Understanding Domestic Abuse in Later Life." Generations 24(2): 39-45.

Baker, Alex. 1975. “Granny battering." Modern Geriatrics 5(8): 20-24.

Bandura, Albert. 1978. "Social learning theory of aggression." Journal of Communication 28(3): 12-29.

Burston, Garden. 1975. "Granny battering." British Medical Journal 3(5983): 592.

Capron, Guénola and Salomón González Arellano. 2010. “Movilidad residential de los adultos mayores y trayectorias de vida familiares en la Zona Metropolitana de Valle de México." Alteridades 20(39), available at: http://www.scielo.org.mx/scielo.php?pid=S018870172010000100006\&script $=$ sci_arttext.

Centro de Estudios Sociales y de Opinión Pública. 2011. “Adultos mayores en zonas metropolitanas de México." En contexto 18, December 13, 2011. Available at: www3.diputados.gob.mx/.../Contexto_No.18 _Adultos_mayores.pdf.

College of Nurses of Ontario. 1993. Abuse of Clients by Registered Nurses and Registered Nursing Assistants: Report to Council on Result of Canada health. Monitor survey of registrants, 1-11.

Consejo Nacional de Evaluación de la Política de Desarrollo Social. 2011. Consideraciones Presupuestales 2012. CONEVAL, Government of Mexico.

De Donder, Liesbeth, Minna-Liisa Luoma, Bridget Penhale, Gert Lang, Ana J. Santos, Ilona Tamutiene, Mira Koivusilta, Anna Schopf, José Ferreira Alves, Jolanta Reingarde, Sirkka Perttu, Tiina Savola, and Dominique Verté. 2011. "European map of prevalence rates of elder abuse and its impact for future research." European Journal of Ageing 8(2): 129-143.

Docampo Santaló, Lourdes, Rita Barreto Lacaba, and Caridad Santana Serrano. 2009. "Comportamiento de la violencia intrafamiliar en el adulto mayor." Archivo Médico de Camagüey 13(6). Available at: http:/ / scielo.sld.cu/scielo.php?pid=S1025-02552009000600010\&scrip $\mathrm{t}=$ sci_arttext. 
El Sol de México. 2014. "Sufren maltrato más de 1.5 millones de adultos mayores en el DF." El Sol de México, May 26. Available at: http://www.oem.com.mx/elsoldemexico/notas/n3405356.htm.

European Parliament. 2010. Report on the role of women in an ageing society. Committee on Women's Rights and Gender Equality.

Homans, George. 1958. "Social Behavior as Exchange." American Journal of Sociology 63(6):597-606.

INEGI (Instituto Nacional de Estadísticas y Geografía). 2012. Estadísticas a Propósito del día del Niño. Datos Nacionales, Aguascalientes, April.

INEGI (Instituto Nacional de Estadísticas y Geografía). 2013. Stadísticas a propósito del Día Internacional de las Personal de Edad. Datos Nacionales, Aguascalientes, October. Available at: http://www.inegi.org.mx/ inegi/contenidos/espanol/prensa/Contenidos/estadisticas/2013/a dultos0.pdf.

Jackson, Jeffrey L. and Renee Mallory. 2009. “Aggression and Violence among Elderly Patients, a Growing Health Problem." Journal of General Internal Medicine 24(10): 1167-1168.

Juárez-Ramírez, Clara, Margarita Márquez-Serrano, Nelly Salgado de Snyder, Blanca Estela Pelcastre-Villafuerte, Maria Guadalupe RuelasGonzález, and Hortensia Reyes-Morales. 2014. “La desigualdad en salud de grupos vulnerables de México: adultos mayores, indígenas y migrantes." Revista Panamá Salud Pública 35(4): 284-290.

INAPAM. 2012. http://www.inapam.gob.mx/index/index.php?sec $=16 \&$ clave_articulo=136\&formato=print (accessed May 5, 2012).

Notimex/Union Guanajuato. 2013. "9 de cada 100 mexicanos son adultos mayores: INEGI." Union Guanajuato, September 27. Available at: http:/ / www.unionguanajuato.mx/articulo/2013/09/27/ciudadano s/9-de-cada-100-mexicanos-son-adultos-mayores-inegi.

Partida-Bush, Virgilio. 2005. "Demographic transition, demographic bonus and ageing in Mexico." In Population Division: Department of Economic and Social Affairs, United Nations expert group meeting on social and economic implications of changing population age structures, UN/POP/PD/2005/16, Mexico City, Mexico.

Pérez-Rojo, Gema, Maria Izal, Ignacio Montorio, and Roberto Nuevo. 2008. "Identificación de factores de riesgo de maltrato hacia personas mayores en el ámbito comunitario." International Journal of Clinical and Health Psychology 8(1): 105-117.

Phillips, Linda R. 1986. “Theoretical explanations of elder abuse: Competing hypotheses and unresolved issues." In Elder abuse: Conflict in the 
family, edited by Karl A. Pillemer and Rosalie S. Wolf, 197-214. Dover: Anburn House Publishing Company.

Quadratín. 2014. "El 70\% de adultos mayores sufre abandono, maltrato o violencia." Quadratín, September 24. Available at: http://www.qua dratin.com.mx/sucesos/El-70-de-adultos-mayores-sufre-abandonomaltrato-o-violencia/

Rhoda, Richard and Tony Burton. 2010. Geo-Mexico: the geography and dynamics of modern Mexico. Frostburg State University, MD.

Rogers, Andrei. 1988. "Age patterns of elderly migration: an international comparison." Demography 25(3): 355-370.

Schiamberg, Lawrence and Gans Daphna. 2000. "Elder Abuse by Adult Children: An Applied Character of Quality of Life." International Journal of Aging and Human Development 50(4): 329-359.

Sethi, Dinesh, Sara Wood, Francesco Mitis, Mark Bellis, Bridget Penhale, Isabel Iborra Marmolejo, Ariela Lowenstein, Gillian Manthorpe, and Freja Ulvestad Kärki (eds.). 2011. European report on preventing elder maltreatment. Copenhagen: World Health Organization Regional Office for Europe.

Sharma, Basundhara. 2012. "Elderly Abuse: An Emerging Public Health Problem." Health Prospect 11: 57-60

Siddiqui, Tasneem. 2012. "Impact of migration on poverty and development." Working Paper 2. Refugee and Migratory Movements Research. The UK Department for International Development (DFID).

Spencer, Charmaine. 1994. Abuse and Neglect of elder adults in institutional settings: an annotated biography. Ottawa: Health Canada.

United Nations. 2013. World Population Ageing 2013. New York: United Nations, Department of Economic and Social Affairs, Population Division.

UNFPA (United Nations Population Fund). 2012. Ageing in the Twenty-First Century: A Celebration and a Challenge. UNFPA and Help Age International.

Vargas-Daza, Emma Rosa, Cecilia Velázquez-Piña, Liliana GaliciaRodríguez, Enrique Villarreal-Ríos and Lidia Martínez-González. 2011. "Tipo de violencia familiar que percibe el adulto mayor." Revista Enfermería del Instituto Mexicano de Seguro Social 19(2): 63-69.

WHO (World Health Organization). 2002. The Toronto declaration on the global prevention of elder abuse. Geneva: World Health Organisation. 